\title{
Nanodiamond suspensions application for heat transfer processes intensification
}

\author{
A S Lobasov ${ }^{1,2}$, A V Minakov ${ }^{1,2}$ and M I Pryazhnikov ${ }^{1,2}$ \\ ${ }^{1}$ Siberian Federal University \\ Krasnoyarsk, Russia \\ ${ }^{2}$ Institute of Thermophysics SB RAS \\ Novosibirsk, Russia
}

\begin{abstract}
Intensification of heat transfer processes is an important and relevant task, and one way to solve it is the use of liquids with various nanoparticles, called "nanofluids." Therefore, an experimental study of the convective heat transfer of nanodiamonds suspensions in a circular straight pipe was carried out in this paper. Ethylene glycol was used as the base liquid. The concentration of nanoparticles ranged from 0.25 vol.\% to 2 vol.\%. The Reynolds numbers varied from 5 to 100. The values of the viscosity and the thermal conductivity coefficients of the resulting nanofluids were also measured experimentally. It was found as a result of these measurements, that the dependence of the thermal conductivity on the concentration of nanoparticles is described by the Maxwell equation. The dependence of the nanofluids viscosity coefficient on the nanoparticles concentration was significantly differ from the Einstein equation, it was much higher. It was found as a result of experimental studies of convective heat transfer, that as the concentration of nanoparticles increases, the heat transfer coefficient also increases, and for a maximum concentration, it was $15 \%$ higher then for the base fluid.
\end{abstract}

Keywords-heat transfer; nanofluid; nanodiamonds; convection; ethylene glycol

\section{INTRODUCTION}

The enhancement of heat exchangers performance becomes a major problem of designing various heat engineering systems and technologies. In some cases, the solution of this problem is quite critical because it determines, in general, the further development of the relevant systems. That situation, for example, takes place in developing of the processors of modern computers, in various micro-electromechanical systems (MEMS), etc. [1]. The main important element of such highefficiency heat transfer systems is the coolant. Over the past two decades, the possibility of using nanofluids i.e. the fluids with dispersed nanoparticles, as an effective coolant has been actively discussed. This is due to the high thermal conductivity of nanofluids, absence of nanoparticles sedimentation, and some other beneficial properties.

A huge number of publications are dealt with the study of heat transfer characteristics of nanofluids. For a long time it seemed that the experimental data obtained are very

The work is performed at partial financial support and by the Ministry of Education and Science of the Russian Federation Government contract with Siberian Federal University in 2018 (No. 16.8368.2017) and was partially funded by Russian Foundation for Basic Research, Government of Krasnoyarsk Territory, Krasnoyarsk Regional Fund of Science to the research project No. 18-48-243019. contradictory. However, many contradictions were removed, when it was proved that these characteristics are primarily determined by the flow regime, whether it is laminar or turbulent [2-5]. It was revealed that heat transfer coefficient in turbulent flow regime of nanofluid may be higher or lower than that in the base fluid depending on the nanofluid characteristics (concentration of nanoparticles, their size and material). On the other hand, in the laminar flow, the heat transfer coefficient of nanofluid always exceeds that for the base fluid. Though, with regard to the extent of this excess, the experimental data are quite contradictory. In [6] it was revealed that the increase in the heat transfer coefficient of water based nanofluid with particles of $\mathrm{Al}_{2} \mathrm{O}_{3}$ having a diameter of $42 \mathrm{~nm}$, amounts to $40 \%$ at a particle volume concentration of $3 \%$. Very close values have been obtained in [7] for this kind of nanofluid, but with particles of $20 \mathrm{~nm}$.

The study of the effect of nanoparticles material on heat transfer was carried out in [8]. The heat transfer of water-based nanofluids with $\mathrm{Al}_{2} \mathrm{O}_{3}$ and $\mathrm{ZrO}_{2}$ particles of the same size (50 $\mathrm{nm})$ were studied. Volume concentration of $\mathrm{Al}_{2} \mathrm{O}_{3}$ nanoparticles ranged from 0.6 to $6 \%$, while that for $\mathrm{ZrO}_{2}$ varied within the range from 0.3 to $1.3 \%$. It was shown that the heat transfer coefficient of $\mathrm{Al}_{2} \mathrm{O}_{3}$-nanofluid was much higher than that of $\mathrm{ZrO}_{2}$-nanofluid. However, the excess in the heat transfer coefficient relative to the base fluid was quite small, just $27 \%$ at a volume concentration of $\mathrm{Al}_{2} \mathrm{O}_{3}$ particles equal to $6 \%$, and just 2-3\% for the nanofluid with $\mathrm{ZrO}_{2}$ particles at a maximum volume concentration. The heat transfer of water based nanofluid with copper particles of $25 \mathrm{~nm}$ was investigated in [9]. It was revealed that at $2 \%$ concentration of nanoparticles, the excess of the heat transfer coefficient was $45 \%$.

The enhance of the heat transfer coefficient of the nanofluids can be explained due to the increase in thermophysical properties of such media. Nanoparticles, because of their small size, have a number of unusual properties that are lacking in the dispersed macroscopic particles. The unusual properties of nanoparticles determine non-standard properties of nanofluids, contained these particles. Most expectations have long been associated with various thermal applications of nanofluids. As late as the first experiments on measurement of their thermal conductivity 
$[10,11]$ shown excellent results: the presence of even small (of the order of a percent fraction) concentrations of solid metal nanoparticles enhanced the thermal conductivity of the base fluid by several percent or even tens of percent. That initiated a number of thermal conductivity measurements of the nanofluids, though the obtained data proved to be surprisingly controversial. It was found that the thermal conductivity of nanofluids, as well as their viscosity not described by the classical theories (see [12-14]). In particular, it was found that the thermal conductivity of nanofluids depends not only on particle concentration but also on particle size. Thus in [15] the water-based nanofluids with $\mathrm{Al}_{2} \mathrm{O}_{3}$ particles was studied, and it was argued that the thermal conductivity coefficient increases with decreasing particles diameter. Similar data for the same nanofluids are given in $[16,17]$. The decrease in thermal conductivity with increasing nanoparticles size was also noted in $[18,19]$ for other nanofluids. In [20] it was asserted that the thermal conductivity coefficient increases linearly with decreasing particles size (the measurements were carried out in water-based nanofluid with nanoparticles of $\mathrm{TiO}_{2}$ and $\mathrm{ZnO}$ ). On the other hand, in [21], based on measurements of thermal conductivity of water-based nanofluids with $\mathrm{SiO}_{2}$ particles was shown just the opposite conclusion: thermal conductivity enhances with the increasing of particles size.

The available data on the degree of thermal conductivity enhancement in nanofluids are quite controversial. Along with the previously mentioned works, which noted a much higher enhancement of the thermal conductivity coefficient than predicted by classical theory, there are also assertions that these measurements can be adequately described by Maxwell's theory [22] (see [11-14,23]). These conflicting data do not allow formulating neither possible mechanisms nor nanofluid thermal conductivity models, though about a dozen of such models are available in literature (e.g. [24-27]).

There is the only hypothesis, which not causes argues among the researcher: as the nanoparticles concentration increases the viscosity of nanofluids increases too. [28-32].

Even a brief review shown a lot of questions and contradictories as well as perspectives of nanofluids usage as a coolant. Therefore, an experimental study of the convective heat transfer of nanodiamonds suspensions in a circular straight pipe as well as an experimental investigation of viscosity and thermal conductivity coefficients of such nanofluids were carried out in this paper.

\section{MEASUREMENT TECHNIQUE AND THE EXPERIMENTAL FACILITY}

Thermal conductivity measurements were performed by non-stationary hot-wire method. The basic electric circuit of the setup is presented in Fig. 1. Wheatstone bridge was used as the basis of the test bench instrumentation to measure an unknown electrical resistance of hot wire. A copper wire with a length of $150 \mathrm{~mm}$ and a diameter of 75 microns was used in the experiments. The wire serves one of the measuring bridge resistors $R_{w}$. The bridge includes also two other resistors: $R_{1}=2 \mathrm{kOhm}$ and $R_{3}=1 \mathrm{Ohm}$ as well as the resistance box $R_{2}$, that needed to balance the bridge. Initially the bridge is balanced and the output voltage does not exceed $10 \mu \mathrm{V}$.
Balancing of the measuring circuit is carried out by a voltage of $0.1 \mathrm{~V}$ from a lab power source GWInstek GPC-3060D applied within a short period of time. Further, the circuit is energized by measuring voltage to record the out-of-balance voltage change of the bridge circuit over the time. Voltage measurement is carried out using a precision voltmeter GWInstek GDM-78261 with increments of $10 \mathrm{~ms}$. In addition, the test fluid temperature was measured by means of chromelcopel thermocouples connected to the TRM-138 meter.

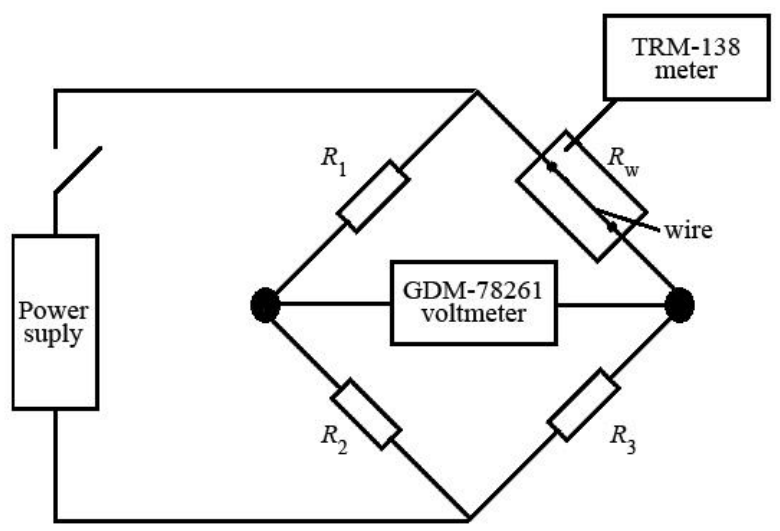

Fig. 1. The electric circuit of the experimental setup

Data processing was carried out in a following way. The initial resistance of the wire is found from the condition of the bridge circuit balance: $R_{w 0}=R_{1} R_{3} / R_{2}$. The change in wire resistance is determined by the ratio

$$
R_{w t}=\frac{R_{3}\left(R_{1}+\frac{V_{o}\left(R_{1}+R_{2}\right)}{V_{i}}\right)}{R_{2}-\frac{V_{o}\left(R_{1}+R_{2}\right)}{V_{i}}},
$$

where $V_{i}$ and $V_{o}$ are the input and out-of-balance voltage of the bridge. Given the dependence of electrical resistance of copper on temperature, it can be determined the temperature change of wire:

$$
\Delta T=\left(R_{w t 2}-R_{w t 1}\right) /\left(\alpha R_{w 0}\right)=\Delta R_{w t} /\left(\alpha R_{w 0}\right),
$$

where $\alpha=0.0003831 / \mathrm{K}$ is the temperature coefficient, predetermined from measurement series of used copper wire resistance at different temperatures. The voltage drop on the wire is given by formula: $V_{R w}=V_{i} R_{w t}\left(R_{w t}+R_{3}\right)$ Then, the linear density of heat flux on the wire is defined as $q=V_{R w}{ }^{2} /\left(L_{w} R_{w t}\right)$, where $L_{w}$ is the length of the wire. In the experiments, a typical value of $q$ was about $10 \mathrm{~W} / \mathrm{m}$.

Eventually, the thermal conductivity coefficient of a fluid is defined as follows: $\lambda=\left(\alpha q R_{w 0}\right) /(4 \pi G)$, where $G$ is the angular coefficient of the linear section taken from the dependence of the wire resistance on the logarithm of time. The coefficient $G$ was calculated by the least squares method. The value of thermal conductivity coefficient was obtained by averaging over ten measurements. During the measurements, the 
nanofluid temperature was maintained constant. In the presented measurements it was equal to $25^{\circ} \mathrm{C}$. The resultant relative measurement error of fluid thermal conductivity coefficient did not exceed $3 \%$.

Measurement of viscosity coefficient of the nanofluid was carried out with the help of "Brookfield DV2T" rotational viscometer with interchangeable spindles. The viscosity of glycol-based nanofluids was measured using LV-1 spindle. The accuracy of the measurement of viscosity was about $2 \%$.

Experimental measurements of heat transfer coefficient of considered nanofluids were carried out using the installation, previously employed for similar purposes and repeatedly tested in $[2-5,14]$. The installation diagram is shown in Fig. 2. The installation is a closed loop with the circulating coolant. The test fluid is pumped through the heated test section to the heat exchanger, where is cooled in the thermostat. The flow rate of the test fluid in the loop is controlled by changing the pump power. The pump power is regulated by the laboratory current transformer. The power supplied to the pump was measured using the Omix meter.

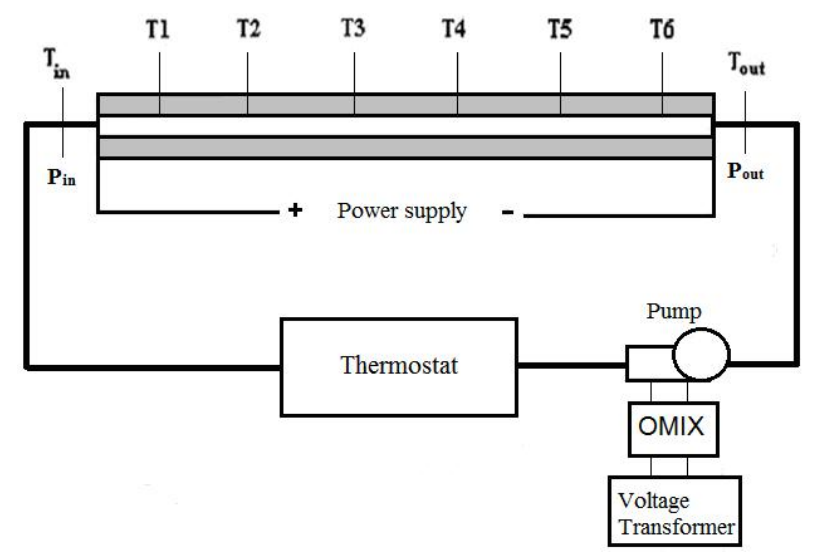

Fig. 2. The scheme of measuring installation

The heated section is a $1 \mathrm{~m}$ long and $6 \mathrm{~mm}$ in diameter stainless steel tube. Thickness of the tube wall is $1 \mathrm{~mm}$. The heating of the tube is carried out by supplying an electric current directly to its wall. That method allows to heat the tube wall by a constant heat flux density. The tube is thermally insulated. The heating power is regulated by a transformer.

Measurements of the local temperature at the tube surface were carried out by six copper-constantan thermocouples fixed at tube wall at an equal distance from each other $\left(T_{i}\right.$ in Fig. 2). Temperature measurements were carried out by TRM-200 meters. In addition, the inlet $\left(T_{\text {in }}\right)$ and the outlet $\left(T_{\text {out }}\right)$ flow temperatures of the heated section were measured by thermocouples (Fig. 2). Pressure drop was measured by a differential pressure meter OVEN PD200. The temperature measurement accuracy was about $0.1^{\circ} \mathrm{C}$, while pressure drop was measured with an accuracy of $1 \%$. Flow rate measurement error did not exceed $1 \%$.

The powder of nanodiamonds was produced by Joint Stock Company Federal Research \& Production Center ALTAI. The sizes of primary particles were 4-6 nm, it was defined by X-ray phase analysis. The aggregate size was $20-2500 \mathrm{~nm}$ and it was obtained by using a scanning electron microscope (see Fig. 3). Density $3.0 \pm 0.1 \mathrm{~g} / \mathrm{cm}^{3}$ was measured by the pycnometric method. The specific surface was $280 \pm 60 \mathrm{~m}^{2} / \mathrm{g}$ and was measured by the BET method. The chemical analysis shown that a diamond phase content was not less than $91.0 \%$. The mass fraction of non-combustible impurities in the solid phase, which was defined by the burning method, was not more than 5.0\%. Chemical impurities are O, N, H (elemental analysis).

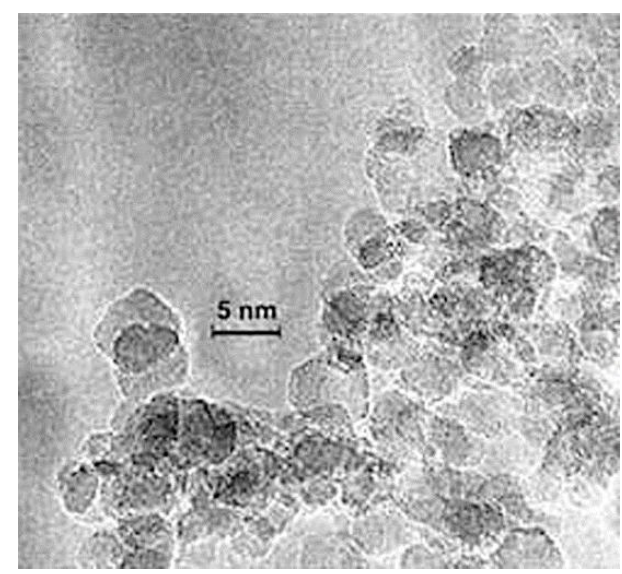

Fig. 3. SEM image of nanodiamonds.

The volume concentration of nanoparticles varied from 0.25 to $2 \%$. Preparation of nanofluids was based on standard two-step process. After adding to the base fluid the required amount of nanopowder, the nanofluid was first exposed to thoroughly mechanical mixing, and then was placed for a halfhour into an ultrasonic disperser 'Sapphire TC-10338' to destruct conglomerates of particles.

\section{RESULTS AND DISCUSSION}

Thermal conductivity measurements were performed by nonstationary hot-wire method mentioned above. In the series of measurements, ethylene glycol was used as the base fluid. Dependences of relative coefficient of thermal conductivity of nanofluids (the ratio of thermal conductivity of nanofluid to coefficient of thermal conductivity of base fluid) on nanodiamonds concentration were obtained. It can be seen in Fig. 4a that as nanodiamonds concentration $\varphi$ increases, the coefficient of thermal conductivity of nanofluids increases too. Furthermore, as one can see in that figure, the dependence of the thermal conductivity of nanofluids is well described by the Maxwell theory (solid line):

$$
\lambda=\lambda_{f} \frac{\lambda_{p}+2 \lambda_{f}+2 \varphi\left(\lambda_{p}-\lambda_{f}\right)}{\lambda_{p}+2 \lambda_{f}-\varphi\left(\lambda_{p}-\lambda_{f}\right)}
$$

where $\lambda_{p}, \lambda_{f}$ are the thermal conductivity coefficients of the particles material and the base fluid.

As mentioned above, the viscosity of nanofluids was measured by a rotational viscometer Brookfield DV2T. The series of measurements were also carried out, as in the previous case, and it was revealed the Newtonian properties of the ethylene glycol-based nanofluids at all considered 
concentrations. The dependence of relative viscosity coefficient of ethylene glycol-based nanofluid on nanodiamonds concentration is shown in fig. $4 \mathrm{~b}$. Also Fig. $4 \mathrm{~b}$ represents that that coefficient is much higher than the same coefficient predicted by Einstein's formula:

$$
\frac{\mu}{\mu_{f}}=1+\frac{5}{2} \varphi
$$

where $\mu_{f}$ is the viscosity coefficient of base fluids.

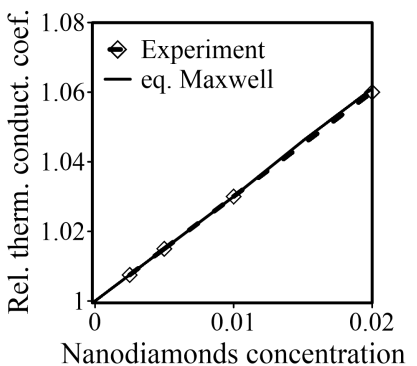

a)

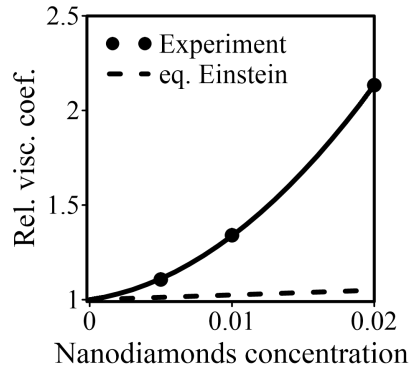

b)
Fig. 4. Relative thermal conductivity and viscosity coefficients of ethylene glycol based nanofluids depending on the nanodiamond particles concentration.

During the experiments, the local heat transfer coefficient was determined by the correlation $\alpha=G C_{p}\left(T_{i}-T_{o}\right) S^{-1}\left(T_{w}-T_{a v}\right)^{-1}$, where $C_{p}$ is the heat capacity of the nanofluid, determined as $C_{p}=\rho^{-1}\left[(1-\varphi) \rho_{f} C_{p f}+\varphi \rho_{p} C_{p p}\right], \rho_{f}, \rho_{p}$ are the densities of the transport fluid and the nanoparticles material, $C_{p f}$ and $C_{p p}$ are the heat capacities of the carrier fluid and the particles material, respectively, $T_{a v}=\left(T_{i}+T_{o}\right) / 2$ is the average temperature of the fluid and $T_{w}$ is the local temperature of the channel wall.

The heat transfer coefficient of the given nanofluid at all concentrations of particles in the considered flow regimes (laminar) is higher than that of the base fluid. The degree of this excess increases almost proportionally to the volume concentration of nanoparticles: $\Delta \alpha=\left(\alpha-\alpha_{0}\right) / \alpha_{0} \sim \varphi$, where $\alpha_{0}$ is the heat transfer coefficient of base fluid. Naturally, the excess in heat transfer coefficient increases with the increasing the flow rate.

Along with the local heat transfer coefficient, average coefficient was determined using the next formula $\alpha_{a v}=G C_{p}\left(T_{i}-T_{o}\right) S^{-1}\left(T_{w, a v}-T_{a v}\right)^{-1}$, where $T_{w, a v}$ is the arithmetic mean temperature of the channel wall, obtained by averaging the data of six thermocouples. The dependence of the average heat transfer coefficient on the Reynolds number $\operatorname{Re}=\rho U d / \mu$ (where $U=4 G /\left(\rho \pi d^{2}\right)$ is the flow velocity calculated by flow rate) is shown in Fig. 5a. The enhancement of heat transfer when using nanofluids at a given Reynolds number is quite significant and grows with an increase in the particles concentration, while increases just slightly with an increase in the Reynolds number. Thus, the heat transfer coefficient for $0.25 \%$ nanofluid is approximately $2 \%$ higher than that for ethylene glycol at almost all Re numbers, while for two-percent nanofluid this increase is already over $15 \%$.
The dependence of the pressure drop in the pipe on the Reynolds number is shown in Fig. 5b. It was fount that the pressure drop for the given nanofluid at all concentrations of particles is higher than that of the base fluid, and the higher the nanoparticles concentration, the more difference between pressure drops for nanofluid and base fluid.

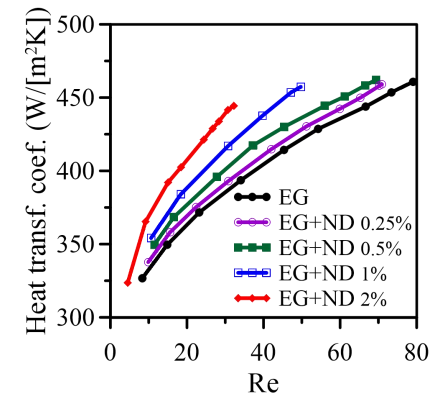

a)

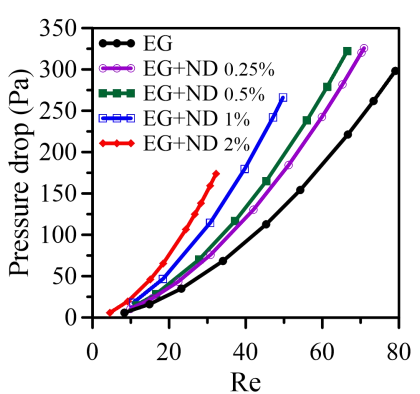

b)
Fig. 5. Relative thermal conductivity and viscosity coefficients of ethylene glycol based nanofluids depending on the nanodiamond particles concentration.

\section{CONCLUSIONS}

The experimental study of the convective heat transfer of nanodiamonds suspensions in a circular straight pipe was carried out in this paper. It was found as a result of experimental measurements of the thermophysical properties of the nanofluid, that the dependence of the nanofluid thermal conductivity on the concentration of nanoparticles is described by the Maxwell equation. The dependence of the nanofluid viscosity coefficient on the nanoparticles concentration was significantly differ from the Einstein equation, it was much higher. It was found as a result of experimental studies of convective heat transfer, that as the concentration of nanoparticles increases, the heat transfer coefficient also increases, and for a maximum concentration, it was $15 \%$ higher then for the base fluid.

\section{REFERENCES}

[1] V.Ya. Rudyak and A.V. Minakov, Modern problems of micro- and nanofluidics, Novosibirsk: Nauka, 2016.

[2] A.V. Minakov, V.Ya. Rudyak, D.V. Guzei and A.S. Lobasov, "Measurement of the heat transfer coefficient of a nanofluid based on water and copper oxide particles in a cylindrical channel", High Temperature, Vol. 53(2), pp. 246-253, 2015.

[3] A.V. Minakov, A.S. Lobasov, D.V. Guzei, M.I. Pryazhnikov and V.Ya. Rudyak, "The experimental and theoretical study of laminar forced convection of nanofluids in the round channel", Applied Thermal Engineering, Vol. 88, pp. 140-148, 2015.

[4] D.V. Guzei, A.V. Minakov and V.Ya. Rudyak, "Investigation of heat transfer of nanofluids in turbulent flow in a cylindrical channel. Fluid Dynamics, 51(2), pp. 189-199, 2016.

[5] A.V. Minakov, D.V. Guzei, M.I. Pryazhnikov, V.A. Zhigarev and V.Ya. Rudyak, "Study of turbulent heat transfer of the nanofluids in a cylindrical channel”, Int. J. Heat Mass Transf., Vol. 102, pp. 745-755, 2016.

[6] D. Wen and Y. Ding, "Experimental investigation into convective heat transfer of nanofluids at the entrance region under laminar flow conditions", Int. J. Heat Mass Transfer, Vol. 47(24), pp. 5181-5188, 2004. 
[7] S.Z. Heris, G. Etemad and M.N. Esfahany, "Experimental investigation of oxide nanofluids laminar flow convection heat transfer", Int Commun. Heat Mass Transfer, Vol. 33, pp. 529-535, 2006.

[8] U. Rea, T. McKrell, L. Hu and J. Buongiorno, "Laminar convective heat transfer and viscous pressure loss of alumina-water and zirconia-water nanofluids”, Int. J. Heat Mass Transf., Vol. 52, pp. 2042-2048, 2009.

[9] S.Z. Heris, G. Etemad and M.N. Esfahany, "Convective heat transfer of a $\mathrm{Cu}$ /water nanofluid flowing through a circular tube", Exp. Heat Transfer, Vol. 22, pp. 217-227, 2009.

[10] H. Masuda A. Ebata, K. Teramae and N. Hishinuma, "Alteration of thermal conductivity and viscosity of liquid by dispersing ultra-fine particles (dispersions of $\gamma$-A12O3, $\mathrm{SiO} 2$, and $\mathrm{TiO} 2$ ultra-fine particles)", Netsu Bussei Japan, Vol .4, pp. 227-239, 1993.

[11] X. Wang, X. Xu and S.U.S. Choi, "Thermal conductivity of nanoparticle-fluid mixture", J. Thermophys. Heat Trans., Vol. 13, No.4, pp. 474-480, 1999.

[12] X-Q. Wang, A.S. Mujumdar, "Heat transfer characteristics of nanofluids: a review", Int. J. Thermal Sciences, Vol. 46, pp. 1-19, 2007.

[13] W. Yu, D.M. France, J.L. Routbort and S.U.S. Choi, "Review and comparison of nanofluid thermal conductivity and heat transfer enhancements", Heat Transfer Eng., Vol. 29, No.5, pp. 432-460, 2008.

[14] K. Kleinstreuer and F. Yu, "Experimental and theoretical studies of nanofluid thermal conductivity enhancement: a review", Nanoscale Research Lett., Vol. 6, No. 229, pp. 1-13, 2011.

[15] C.H. Chon, K.D. Kihm, S.P. Lee and S.U.S. Choi, "Empirical correlation finding the role of temperature and particle size for nanofluid (A12O3) thermal conductivity enhancement", Appl. Phys. Lett., $87: 153107,2005$.

[16] C.H. Li and G.P. Peterson, "Effect of particle size on the effective thermal conductivity of A12O3-water nanofluids", J. Appl. Phys., 101:044312, 2007.

[17] H.A. Mintsa, G. Roy, C.T. Nguyen and D. Doucet, "New temperature dependent thermal conductivity data for water-based nanofluids", Int. J. Thermal Sci., Vol. 48, pp. 363-371, 2009.

[18] M. Chopkar, S. Sudarshan, P.K. Das and I. Manna, "Effect of particle size on thermal conductivity of nanofluid”, Metal Mater Trans., Vol. 39, pp. 1535-1542, 2008.

[19] J. Hong, S.H. Kim, D. Kim, "Effect of laser irradiation on thermal conductivity of ZnO nanofluids”, J. Phys., Conference Series, Vol. 59, pp. 301-304, 2007.
[20] S.H. Kim, S.R. Choi and D. Kim, "Thermal conductivity of metal-oxide nanofluids: Particle size dependence and effect of laser irradiation", ASME J. Heat Transf., Vol. 129, pp. 298-307, 2007

[21] G. Chen, W. Yu, D. Singh, D. Cookson and J. Routbort, "Application of SAXS to the study of particle size dependent thermal conductivity in silica nanofluids", J. Nanopart. Res., Vol. 10, pp. 1109-1114, 2008.

[22] J.C. Maxwell, A treatise on electricity and magnetism, Oxford: Clarendon Press, 1881.

[23] W. Rashmi, M. Khalid, S.S. Ong and R. Saidur, "Preparation, thermophysical properties and heat transfer enhancement of nanofluids", Materials Research Express, Vol. 1., pp. 032001, 2014.

[24] P.M. Kumar, J. Kumar, R. Tamilarasan, S. Sendhilnathan and S. Suresh, "Review on nanofluids theoretical thermal conductivity models", Engineering Journal, Vol.19, No 1, pp. 67-83, 2015.

[25] J.-H. Lee, S.-H. Lee, C. Choi, S. Jang, S. Choi, "A Review of Thermal Conductivity Data, Mechanisms and Models for Nanofluids", Int. J. Micro-Nano Scale Transp, Vol. 1, Is. 4, pp. 269-322, 2010.

[26] A. Dmitriev, "Fluctuation hydrodynamics, thermophoresis of nanoparticles and heat transfer in nanofluids", Proc. the 3th Micro/Nanoscale Heat \& Mass Transfer Int. Conf. March 3-6, 2012, Atlanta, Georgia, USA. MNHMT2012-75205.

[27] S.A. Angayarkanni and J. Philip, "Review on Thermal Properties of Nanofluids: Recent Developments", Adv. Colloid and Interface Sci., Vol. 225, pp. 146-176, 2015.

[28] S.Sh. Hosseini, A. Shahrjerdi and Y. Vazifeshenas, "A review of relations for physical properties of nanofluids", Australian J. Basic and Applied Sci., Vol. 5(10), pp. 417-435, 2011.

[29] I.M. Mahbubul, R. Saidur and M.A. Amalina, "Latest developments on the viscosity of nanofluids", Int. J. Heat Mass Transf., Vol. 55. pp. 874885, 2012.

[30] S.M.S. Murshed and P. Estellé, "A state of the art review on viscosity of nanofluids', Renewable and Sustainable Energy Reviews, Vol. 76, pp. 1134-1152, 2017.

[31] D.H. Koca, S. Doganay, A. Turgut, I.H. Tavman, R. Saidurd and I.M. Mahbubulf, "Effect of particle size on the viscosity of nanofluids: A review", Renewable and Sustainable Energy Reviews, Vol. 82., pp. 1664-1674, 2018.

[32] A.K. Sharma, A.K. Tiwari and A.R. Dixit, "Rheological behaviour of nanofluids: A review", Renewable and Sustainable Energy Reviews, Vol. 53, pp.779-791, 2016. 